States of matter

States of Matter. (Prentice-Hall Physics Series.) By David L. Goodstein. Pp. xii +500. (Prentice-Hall: Englewood Cliffs, N.J., March 1975.) £12.50.

THIS book is based on lectures given at Caltech as an advanced year-long course in applied physics. It is an outstanding example of the nutritious pabulum fed to American postgraduate scientists, and indeed constitutes a very meaty dish. The first chapter (about 90 pages), based largely as the author indicates on Landau and Lifshitz, provides a rigorous introduction to thermodynamics and statistical mechanics. The following chapters then deal with the perfect gas (40 pages), solids (70 pages), liquids and interacting gases (90 pages), some special states including superfluidity, superconductivity and magnetism (90 pages) and finally critical phenomena and phase transitions including scaling laws (50 pages). Each chapter concludes with some shrewd comments on bibliographical sources and some well-tried, rather demanding examples.

Throughout the book the main themes are tackled in terms of thermodynamics and statistical mechanics. This unified, integrated treatment has many attractive features. It has the disadvantage, however, that in some cases the approach is somewhat tortuous. Again the mathematical analysis is often heavy going and rather formal. On the other hand the accompanying discussion, which is expressed in a verbal rather than a written style is always lively and communicative and reflects a first-hand mastery of the issues under review. Those who find the analysis too tough will always find the author's comments illuminating: they breathe life into the dry bones of the formal analysis and provide a fresh and often entertaining insight into the physics of the problem under discussion. There are also some agreeable personal touches-for example, on quantised entities ending in -ons, such as phonons, photons, and so on. "Even human populations have quantised units called persons." On classical theories: so called not necessarily to distinguish them from quantum mechanical, "but simply because classical is what we usually call the theory that came just before the one we believe now." On the irreversible tendency for entropy to increase he quotes the famous quatrain of Omar Kayyam (". . . the moving finger ... ") with the comment that "there have been many other statements of the Second Law, all of them less elegant."

The chapter on liquids, fascinating as it is, probably provides material least familiar to the student, and the physics seems to be overlaid too heavily with computational tricks for calculating the interaction of atomic clusters. Again the inadequacy of pairwise additivity could have been made more concrete if the author had compared, for example, the lattice energy of solid argon with that deduced from pairwise calculations: and if his fifth chapter had dealt with dielectrics (as well as magnetism) he could have linked the problem of additivity with the dielectric properties of matter in the condensed state. This in turn provides a bridge with the van der Waals'

\title{
Aged Ecuadoreans
}

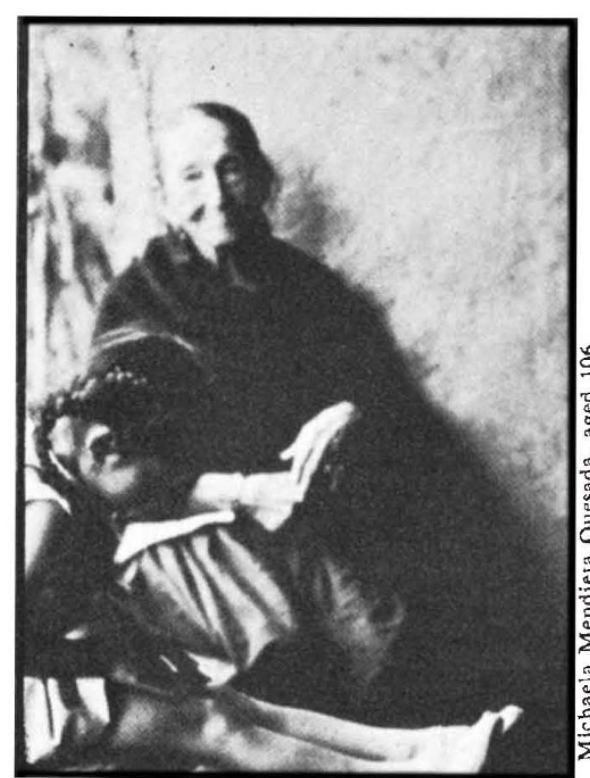

The Centenarians of the Andes. By David Davies. Pp. $128+17$ photographs. (Barrie and Jenkins: London, July 1975.) $£ 3.95$.

Populations containing numerous centenarians and supercentenarians have been reputed to exist in the Ecuadorean Andes since 1825 (G. Coggeshall, 1825, Voyages to various parts of the world), and have recently been noted by Leaf (Youth in old age, 1975). This book is an anecdotal but informative study of the distribution, way of life and documentary authenticity of centenarians in Vilcabamba, who have been fairly extensively studied, at least from the standpoint of documentation by Dr Miguel Salvador for the Ecuadorean Government. Ages of 140 and 150 years have been reported, but equally remarkable is the state of physical preservation of people throughout old age. Dr Davies' book properties of liquids and solids. Finally, the author quotes the opinion of some scientists that plasmas constitute the fourth state of matter: it would do no harm if applied physicists were to be taught instead about the colloidal state. This is not only of great importance, it also offers scope for some very nice physics. But these are personal opinions rather than criticisms.

Dr Goodstein's heroes, to judge from his references and comments, are Landau and Lifshitz, Mott and Jones, G. I. Taylor and Galileo Galilei. This fine sense of scientific discrimination and catholicity of interests characterise the stimulating and challenging book he has written.

David Tabor contains no demographic tables, so that the population breakdown cannot be ascertained from it. As in Abkhasia, interest naturally focusses on the authenticity of the high age recordsthese seem better documented than in Abkhasian Muslims, by reason of the care devoted to Catholic birth and burial registers.

At present the high age population seems to be confined to a small enclave of mountain villages, but there are rumours of similar longevity in other parts of the Andes not yet investigated. In the villages around Vilcabamba longevity seems to affect at least three distinct population types. Possible causes of survival (genetic endowment, hybrid vigour, low calorie or low fat diet, particular dietary constituents, environment, and absence of psychosocial pressure to age) are discussed, but there is as yet no evidence to support any one of these factors, except perhaps isolation from viruses and continued acceptance of 'old' activity, which clearly operates in the field of work and of sexuality. The environment but not the diet resembles that of Abkhasia, where longevity is reportedly geographic rather than specifically ethnic, affecting Russians, Abkhases and Jews who live in the area.

Dr Davies' treatment is of necessity that of a travelogue, illustrated with some good photographs. A proper monograph giving the demographic picture and the true prevalence of centenarism is overdue, and it is to be hoped, in view of the great interest of the model, that Dr Salvador and the Ecuadorean Government will provide us with one to amplify a previously circulated report (M. Salvador, et al., 1972. Vilcabamba, tierra de longevos, Quito: Casa de la Cultura Ecuatorian).

Alex Comfort 